\title{
Systematized methods for the development of Product-Service Systems: a systematic literature review
}

\author{
Antonio Erlindo Braga Junior ${ }^{a}$, José Carlos de Toledob, Mario Orestes Aguirre González \\ anniversidade do Estado do Pará \\ bUniversidade Federal de São Carlos \\ Programa de Pós-Graduação em Engenharia de Produção, Universidade Federal do Rio Grande do Norte \\ e-mails: erlindo@uepa.br; toledo@dep.ufscar.br, mario@ct.ufrn.br
}

\begin{abstract}
Research on implementation of Product-Service Systems (PSS) in manufacturing companies has grown steadily and many methods have been published. This paper aims to identify and analyses existing methods on the implementation of PSS through a systematic literature review, focusing on methods with information considered enough for effective application. It was identified 1716 papers published among January 2006 and December 2018. Forty-six methods were identified; of which only 5 met the criteria established in the research for practical application. There is no convergence in the literature for indication of a predominant method, or even a guide to select the appropriate method for the business context. The approaches, procedures and characteristics of the methods are equivalent. No predominance of some over the others, about better results or efficiency, was observed. Despite the large volume of information identified, there is a gap in the literature, which is the lack of papers that guides effectively to develop a PSS and with detailed information for implementation.
\end{abstract}

Keywords: Product-Service Systems, PSS implementation, PSS method, systematic literature review, implementation.

\section{Introduction}

Competition among manufacturing companies is in a transition, new products and technological competitive advantages no longer promote the same differentiation over time, since the competitors adapt quickly (MATTHYSSENS; VANDENBEMPT; BERGHMAN, 2006). In addition, clients' demands are more comprehensive and pursue broader solutions for their needs, going beyond fragmented responses offered by suppliers.

More integrated solutions, including products and services, may be an answer to these problems of competitiveness and of greater market demand. Servitization of manufacturing has received a great deal of attention, because it delivers products integrated with services, adding value to products by adding services (BAINES et al., 2016).

Product-Service Systems (PSS) is a business model where the company operates to deliver this new value, making the Servitization process real (GOEDKOOP et al., 1999; MONT, 2001). Manufacturing companies, which want to offer services merged in their products, need to carry out transformations in their structure and processes (ALVAREZ, 2012). These transformations must be performed through the existing methods for PSS implementation.

Introduction of a PSS is difficult for companies, which must reconsider their organization and business model traditionally based on mass production and process optimization. To favour this transition, it is necessary to use a method that guides the PSS implementation process. This method differs from the traditional product development, since PSS is influenced by several factors not necessarily included during the product development (MAUSSANG; ZWOLINSKI; BRISSAUD, 2009).

There is a range of tools and methods for PSS implementation. However, there is no critical and indepth assessment of their performance in practice. A more widespread adoption of the PSS requires a better understanding of its practices, methods for value assessment and organizational changes (BAINES et al., 2007).

Research is necessary to enable companies to develop an adequate integration between products and services. Methodologies, tools and procedures must provide support to professionals in order to create services that are economically and environmentally beneficial, and they must be tested and validated in organizations (SAKAO; SANDSTRÖM; MATZEN, 2009). Organizations also need to know how to initiate the transformation process for Servitization, showing where they must start and the route to be followed to achieve success in this change (BAINES; LIGHTFOOT, 2013). 
Vasantha et al. (2012) and Baines and Lightfoot (2013) state that there are several difficulties in implementing a PSS because it demands new tools and methodologies, and these authors indicate examples to support this activity. In their study of the methods for PSS implementation, they consider that the implementation process of a PSS must be individualized due to the interrelations between products and services, and they reinforce that the research in this area is in initial phase.

Beuren et al. (2014) have suggested contributions to improve the knowledge about the use of the PSS in practice and have stated that researches have to be performed to explore the tools and methods for its implementation. In this context, this paper presents a broad view, through a systematic literature review, of the existing methods for PSS implementation. The methods with the greatest availability of information to make the implantation feasible are presented, since there is a lack of information in most publications on methods for PSS implantation.

\section{Research methods}

A systematic literature review was carried out following the guidelines proposed by Levy and Ellis (2006), Biolchini et al. (2007) and Dyba and Dingsoyr (2008). Based on these guidelines, three phases were established for the execution of the systematic literature review: input, processing and output.

\subsection{Input}

They are the elements that define the research protocol: research question, objectives, primary sources, search strings, inclusion criteria, qualification criteria and search filters.

Research question and review objectives: What are the existing methods for PSS implementation? This review aimed to identify and classify the existing Product-Service System implementation methods in the literature, prioritizing the identification of the methods presented in a more operational way and already tested in practice

Primary sources: We sought to identify primary sources on the subject, define the keywords, survey the theoretical basis, and identify the main authors and relevant papers. These papers give a broad and comprehensive view of the subject and are, for this reason, a good start for this type of survey to identify the necessary keywords.

Search strings: The keywords used were: Product-Service System, Product Service System, Method, Methodology, Servitisation (UK English spelling), Servitization (US English spelling), forming the string: ("product-service system" OR "product service system" OR "servitisation" OR “servitization") AND (Method OR methodology).
Inclusion criteria: The period chosen was from January 2006 to December 2018, since it comprises the most recent papers on the subject. The survey was conducted in the Engineering Village, Web of Science, Scopus and Science Direct databases where we searched for journals, congress, books, book chapters, theses, dissertations and monographs. We only accepted English-language publications containing the description of PSS implementing methods, or its application, or publications reviewing the literature on this theme.

Qualification criteria: To determine the importance of the papers selected for the research the following qualification criteria were established: to present case studies of PSS implementation, to have detailed information about the methods used and the impact factor of the journal.

Search filters: Search filters applied to the papers collected were: FILTER 1 - reading the title of the paper, abstract and keywords; FILTER 2 - reading the introduction and conclusion; FILTER 3 - reading the full paper. To support the activity of filtering the papers and data extraction, the StArt* software was used. For the archiving, reading and recording of annotations on the papers, Mendeley software was used.

\subsection{Processing}

The search results generated by the filters were exported to StArt, excluding duplicated papers. Then the three filters were applied to select for relevant papers. These phases were accomplished with the support of Mendeley and StArt, for the filing and recording of the paper's evaluations, respectively. Papers that met the inclusion criteria, after the application of the three filters, formed the final group of selected papers.

\subsection{Output}

The analysis and discussion of collected data generated information that met the objectives of the research.

\section{Data analysis}

A total of 1716 papers were identified, 856 were found duplicated in the databases. The remaining 860 papers were filtered to verify if they met the inclusion criteria, by reading the title and the abstract, and then, the same filtering criteria was used for the papers' introductions and conclusions. We identified 77 papers that were consistent with the objective of the research, to perform the complete reading and the data extraction phase.

Among the 77 papers selected, there was an irregular distribution of publication from 2006 to 2010 . There was no publication record on the searched topic in 2008. From

* More details on http://lapes.dc.ufscar.br/tools/start_tool 
2011 onwards, the searched topic increased in relevance with 15 publications in 2015, doubling the number of publications compared to the previous year. In 2016, 18 publications were identified. There was a fall in 2017 and 2018 with 5 publications and 6 publications, respectively (Figure 1).

We identified 19 countries where the first author's institution is based. Despite the diversity, 8 countries constitute $78 \%$ of the production in the period, the other 11 countries contributed with $22 \%$ of the publications. Italy leads the number of publications with 20 papers, representing $26 \%$ of the total. Only 1 publication from the USA was observed in the period, despite being a country with a tradition of worldwide scientific research in management and services. Figure 2 shows the distribution of publications by country.

The papers can be classified into four groups: a) papers that present at least one method for implementing a PSS (33 papers); b) papers that present literature reviews on methods for PSS implementation (8 papers); c) papers that describe tools for the PSS implementation (32 papers); and d) papers that present case studies showing examples of the method application (6 papers). Figure 3 shows the distribution of papers according this classification.

Some authors adopt the term "method", others "methodology" referring to the same content. In this article, "method" will be used to designate the steps for developing an PSS. While "tool" refers to support instruments for

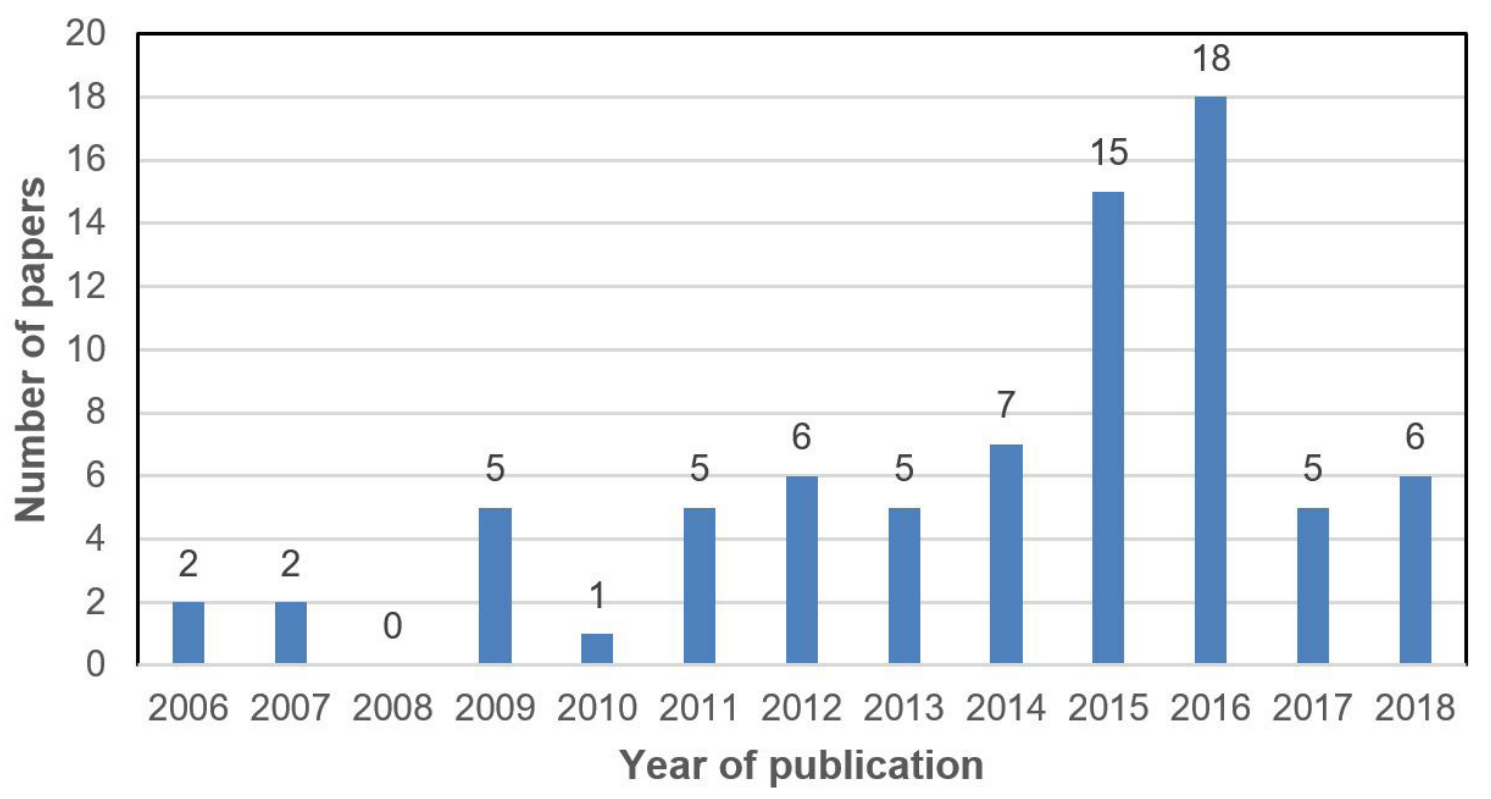

Figure 1. Publications distribution from 2006 to 2018.

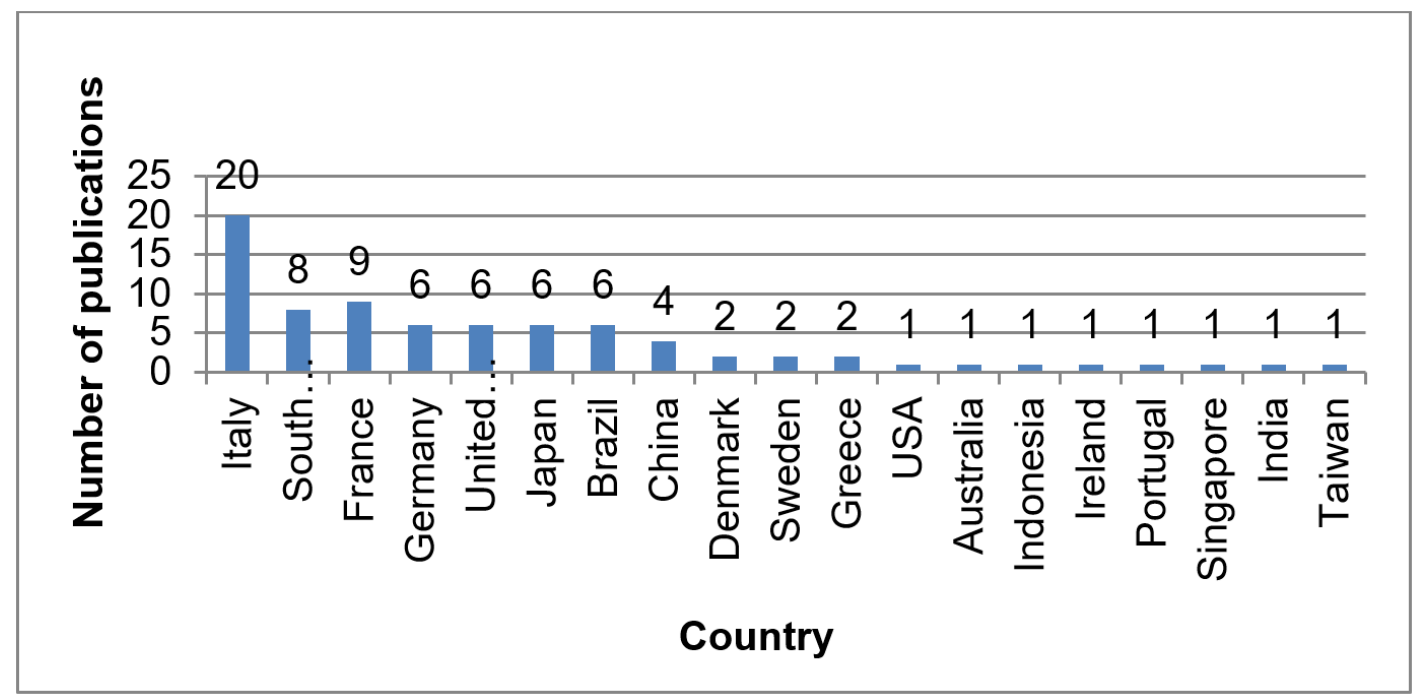

Figure 2. Distribution of publications by country. 


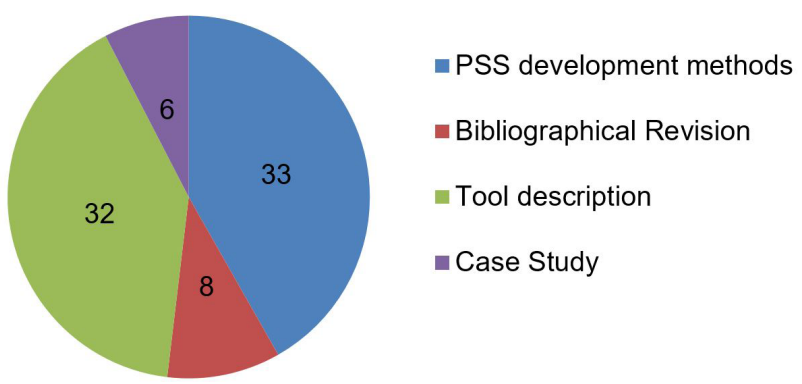

Figure 3. Paper distribution according to the proposed classification. carrying out activities of the method. The methods that have been published in papers, as well as those that appear cited in literature reviews, are presented in Table 1 with the respective authors.

Regarding the denomination of the methods, it is observed that there is little concern to establish a brand name and to differentiate itself from the other methods. The definitions of the names do not facilitate their memorization and the designations used are brief descriptions of a method's characteristics, techniques and applications. There are exceptions such as AEPSS (Austrian eco-efficient PSS

Table 1. Methods identified.

\begin{tabular}{|c|c|}
\hline METHODS & AUTHOR(S) \\
\hline Method based on functional analysis and agent-based value design & Maussang et al. (2007) \\
\hline $\begin{array}{l}\text { Methodology for the realization of product-oriented and use-oriented PSS for consumer } \\
\text { products }\end{array}$ & Yang et al. (2009) \\
\hline $\begin{array}{l}\text { Product-service system design methodology: from the PSS architecture design to the } \\
\text { products specifications }\end{array}$ & Maussang, Zwolinski and Brissaud (2009) \\
\hline $\begin{array}{l}\text { Methodology to manufacturing companies selling capital goods in B2B markets to deliver } \\
\text { integrated solutions }\end{array}$ & Visintin (2010) \\
\hline PSS Layer Method & Sakao, Paulsson and Mizuyama (2011) \\
\hline Method for knowledge-based PSS design support & Akasaka et al. (2012a) \\
\hline Methods to support PSS conceptual design & Akasaka et al. (2012b) \\
\hline Fast Track Total Care & Vasantha et al. (2012) \\
\hline Methodology for Product-Service Systems (MEPSS) & Clayton, Backhouse and Dani (2012) \\
\hline Service CAD & \multirow{7}{*}{ Vasantha et al. (2012) } \\
\hline Service Model Service Explorer & \\
\hline Integrated product and service design processes & \\
\hline PSS Design & \\
\hline Heterogeneous IPS concept modelling & \\
\hline The dimensions of PSS Design & \\
\hline The design process for the development of an integrated solution & \\
\hline Designing eco-efficient services (DES) & Clayton, Backhouse and Dani (2012) \\
\hline Methodology to emphasize the innovative thinking in PSS conceptual generation stage & Yang, Xing and Lee (2013) \\
\hline Methodology for product-service systems development & Marques et al. (2013) \\
\hline Systematic design framework for PSS & Kim et al. (2013) \\
\hline SErvice Engineering Methodology (SEEM) & $\begin{array}{l}\text { Rondini et al. (2014) } \\
\text { Mahut et al. (2015) } \\
\text { Pezzotta et al. (2016a) }\end{array}$ \\
\hline QFD-based methodology to support Product-Service design in manufacturing industry & $\begin{array}{l}\text { Peruzzini, Marilungo and Germani (2014a) } \\
\text { Peruzzini, Marilungo and Germani (2015) }\end{array}$ \\
\hline Method for operationalizing the generic PSS development process & Nguyen et al. (2014) \\
\hline $\begin{array}{l}\text { Methodology to support ideation and preliminary design of sustainable P-S solutions within } \\
\text { industrial chains involving large enterprises as well as small and medium enterprises }\end{array}$ & Peruzzini, Marilungo and Germani (2014b) \\
\hline Generic design methodology for different types of PSS & Tran and Park (2014) \\
\hline Integrated methodology to support the PSS design process into a Virtual Enterprise & Marilungo, Peruzzini and Germani, (2015) \\
\hline New PSS design method of a pneumatic energy system & Lucile, Alan and Daniel (2015) \\
\hline Integrative innovation and business model design method (iSIM) & Krueger et al. (2015) \\
\hline PSS design methodology based on the integrated product and service design requirements & Sutanto et al. (2015) \\
\hline PSS design guideline based on Software Engineering Methods and Theory (SEMAT) & Muto, Kimita and Shimomura (2015) \\
\hline Service-oriented PSS development process & Kim et al. (2015) \\
\hline
\end{tabular}


Table 1. Continued...

\begin{tabular}{|c|c|}
\hline METHODS & AUTHOR(S) \\
\hline The Design Process for the Development of an Integrated Solution & \multirow{3}{*}{ Mendes et al. (2015) } \\
\hline Service Model & \\
\hline Integrated Product and Service Design Process & \\
\hline Service Engineering (SE) & \multirow{7}{*}{ Mahut et al. (2015) } \\
\hline Functional Product Development (FPD) & \\
\hline Architecture for service engineering & \\
\hline Austrian eco-efficient PSS project (AEPSS) & \\
\hline The Kathalys method & \\
\hline The design exploration process $(D E P)$ & \\
\hline The service system design (SSD) approach & \\
\hline Product Service Co-evolution and Management System (PSCoMS) & Marilungo et al. (2016) \\
\hline DIVERSITY Methodology & Pezzotta et al. (2016b) \\
\hline QFD-based methodology to design sustainable PSS & Peruzzini and Marilungo (2016) \\
\hline Conceptual framework for Product Service System design for machine tools & Zine et al. (2016) \\
\hline PSS design framework for customization & Song and Sakao (2017) \\
\hline
\end{tabular}

project) and PSCoMS (Product Service Co-evolution and Management System), which have acronyms of the denomination formed by a brief description of the methods.

\section{Description and analysis of methods}

A set of criteria was established to select the methods that have complied with the final filtering:

a) The publication must be in a peer-reviewed journal

b) The method must cover the entire PSS implementation process

c) The method must be detailed enough to allow its analysis and use

d) There must be practical application cases.

The methods that met the established criteria were: Service-oriented PSS development process; Generic design methodology for different types of PSS; Product-service system design methodology: from the PSS architecture design to the products specifications; MEPSS - Methodology for Product-Service Systems; and PSS design framework for customization. An individual analysis of these methods is presented.

\subsection{Service-Oriented PSS development process}

It is a specific service-oriented method for PSS, described by Kim et al. (2015), in which the product is incorporated into existing services. It was developed with the objective to increase service competitiveness and was derived from methods of product development, service development and PSS development case studies.

Developing and manufacturing products is not an obvious task for service providers. Products depend on technology, equipment and facilities, while services depend on humans. Thereby, service providers should seek partnerships with product manufacturers to develop service-oriented PSS and to collaborate closely in their development (KIM et al., 2015).

Service-oriented PSS development process has two relevant features. The first one starts with the client needs and how this relates to the service currently provided; this will be used later to define the product functions, and, subsequently, new services are developed by combining the existing service with the new product. The functions required for the product are derived from customer needs for the service, and the product makes the service more competitive. The second feature relates to the difficulty of service providers in development and manufacturing products, so that manufacturers receive greater emphasis.

In view of these features, the method foresees the interaction of two distinct activities, the service providing and the product manufacturing, which carry out activities either in isolation or together, depending on the stage of development. The separation between product and service providers is a hallmark of this method. This makes its applicability restricted to cases in which the products are the means for the execution of services and in cases where products and services are not of equal importance to the customer.

The method consists of four steps: Strategic Planning, Idea Generation and Selection, Service Design and Product Development (Figure 4). The Strategic Planning is carried out exclusively by the service provider that establishes the objectives to be achieved by the PSS. These objectives influence in determining the criteria for the choice of partner that will develop and manufacture the product and must meet three guidelines: technological alignment 


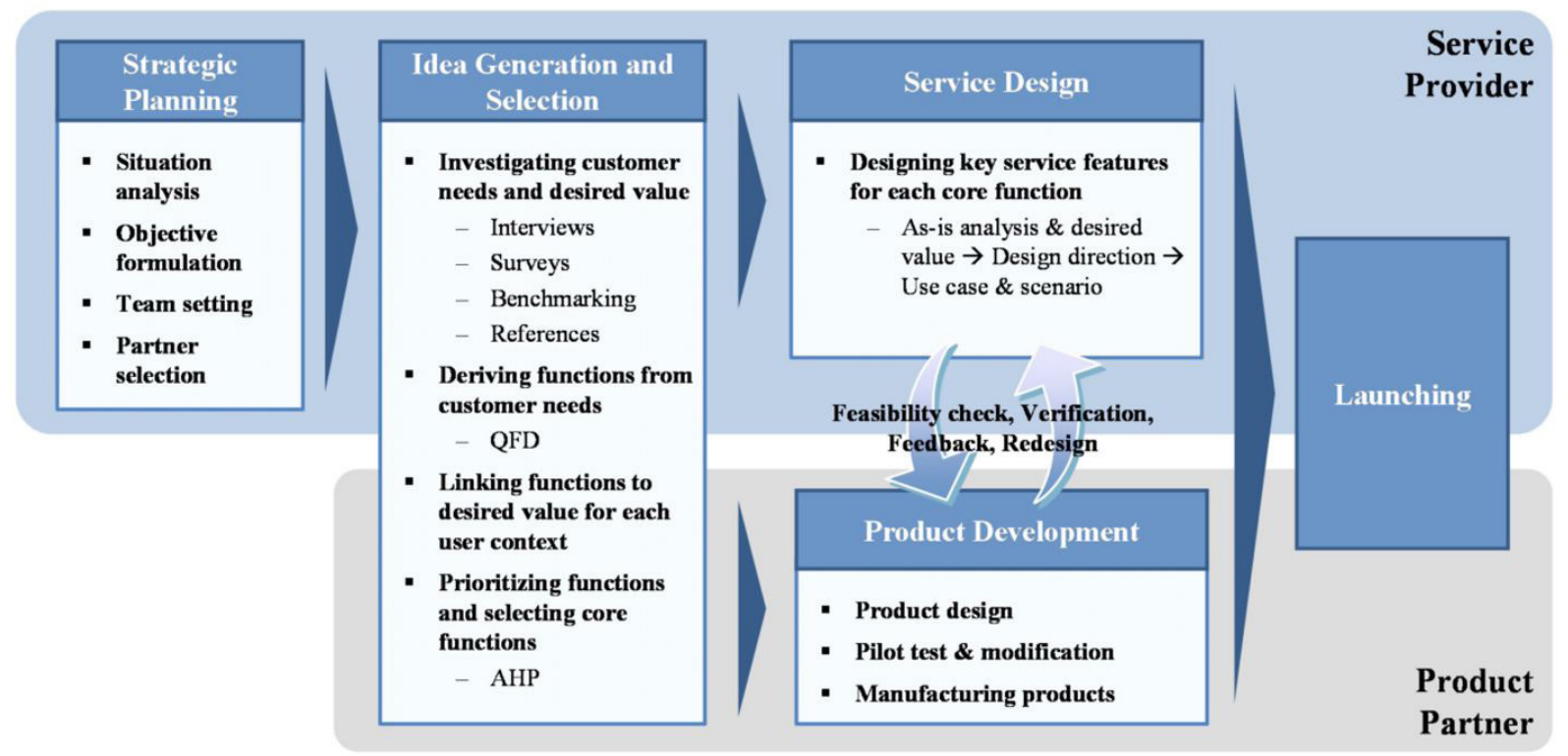

Figure 4. Service-oriented PSS development process by Kim et al. (2015).

(technological capacity, complementarity of resources and knowledge bases), strategic alignment (motivation and alignment of the objectives with the potential partner), and relational alignment (compatibility among corporate cultures, inclination for change and long-term orientation). The Idea Generation and Selection step is carried out by both partners. The Service Design step is achieved by the service provider and the Product Development by the product manufacturer.

Between each step, an intermediate assessment is performed, and its results are used in a "back loop" scheme to improve the activities done in that step. This PSS development method is a hybrid method of sequential and parallel activities. This is justified by the "Idea Generation and Selection" step is performed after the "Strategic Planning" step, the product development is done in parallel to the services development.

A key feature to the successful application of this method is to reach a consensus between service and product through an effective communication and interaction between the two actors. For this purpose, the product partner must know the results of the service design to customize the product design. Thus, it is possible to consider its feasibility, to carry out verification and feedback as well as the redesign based on the results of these actions. These steps must be performed when considering the results of the Product Development, which must be presented to the service provider partner.

Some deficiencies are observed in this method. The first one is that, despite the concern for information exchange between the service and product developers, there is no guarantee that the result will be an integrated product-service system that will generate value for customers, which would characterize a PSS. The second, more evident than the mentioned above, is the restriction of application of this method only to service-oriented PSS.

\subsection{Generic design methodology for different types of PSS}

This method is based on previous studies about PSS development, on analysis of the differences among PSS types, on analogy between product and service development processes, as well as on the benefits of enabling a co-creation process in PSS development and was proposed by Tran and Park (2014). This method is an option to develop several types of PSS and considers the user participation, the business model and the organizational structure during PSS development. To optimize the development process, the method considers the PSS main elements: product, service, business model, stakeholders and organizational structure. To develop a more comprehensive method, three approaches are presented for PSS development:

a) For product-oriented PSS, it is suggested that the "product component" must be designed prior to the "service component", which must be considered as an additional value to the product;

b) For results-oriented PSS, the "service component" must be designed prior to the "product component", because in this instance, the customer often does not care about the product, but is mainly interested in value proposition and, consequently, in the service that this value offers. In this case the product is considered as a medium through which a service is delivered. 
c) For use-oriented PSS, design may resemble product-oriented or results-oriented, depending on the importance of the product or the service in the system.

The steps of the method are: "Requirement Analysis", "Design and Integration", "Test and Refinement", "Implementation" and "Retirement \& Recycling". These steps are structured as shown in the Figure 5. At the end of each step, checks are carried out for its approval and then beginning the next step.

The Table 2 shows the activities performed at each step, the stakeholder's involvement and what is verified at the checkpoint at the end of each step. Nevertheless, there are no details regarding tools or techniques to comply with these steps, which may cause difficulties for the developer or even errors in performing these activities.

The method considers stakeholder participation in all steps of the development process to ensure compliance with project requirements. This method presents similar steps to others observed in this research, since it is also based on the methods of product development. However, there isn't an in-depth strategic market analysis where PSS would operate.

An advantage of this method is to present different development proposals for different types of PSS. This feature emphasizes the particularities of each type and allows reducing the chances of errors in the development of PSS. Another advantage is the participation of stakeholders, such as the user and the providers, during the development process.

\subsection{Product-service system design methodology: from the PSS architecture design to the products specifications}

The objective of this method is the development of PSS emphasizing the technical specifications of engineering for the development of the physical objects involved in the PSS, relative to the requirements of the whole system. This emphasis was established because its proponents understand that PSS development methods focus on the system and do not sufficiently specify the criteria for product development.

The method was proposed by Maussang, Zwolinski and Brissaud (2009) and consists of the following steps:

CUSTOMER'S REQUIREMENTS - In this stage, the expectations, needs and specifications of the client and other stakeholders are raised throughout the PSS life cycle. This survey is carried out from the analysis of the external environment to the PSS to be developed.

FUNCTIONS DEPLOYMENT - Once the demands have been characterized, the next step is to design the solutions that will guarantee the result required by the customer. This analysis leads to the definition of the technical functions that the PSS must fulfil and the solution principles to be conceived.

SCENARIOS - From the proposed solutions, scenarios are developed for the functions, and for each scenario different arrangements of components, physical object or service unit are chosen, to meet the established requirements. Then a flow chart is created to represent the arrangements among the components that perform the

Table 2. Activities performed by the GENERIC DESIGN METHODOLOGY FOR DIFFERENT TYPES OF PSS.

\begin{tabular}{|c|c|c|c|}
\hline Design Step & Design activities & Stakeholder involvement & Checkpoint \\
\hline PSS idea development & $\begin{array}{l}\text { - Opportunity scanning } \\
\text { - Business model } \\
\text { - PSS type } \\
\text { - PSS idea } \\
\end{array}$ & $\begin{array}{l}\text { - User: idea generation, idea } \\
\text { evaluation } \\
\text { - Others: idea generation, idea } \\
\text { evaluation }\end{array}$ & $\begin{array}{c}\text { G1 } \\
\text { Validity of PSS ideas }\end{array}$ \\
\hline PSS planning & $\begin{array}{l}\text { - Resources allocation } \\
\text { - Team formation } \\
\text { - Market segmentation } \\
\text { - PSS scheduling }\end{array}$ & $\begin{array}{l}\text { - User: PSS portfolio } \\
\text { evaluation } \\
\text { - Others: technology } \\
\text { availability (support system) }\end{array}$ & $\begin{array}{c}\text { G2 } \\
\text { Feasibility of PSS plans }\end{array}$ \\
\hline Requirement analysis & $\begin{array}{l}\text { - Needs identification } \\
\text { - Needs analysis } \\
\text { - Benchmarking } \\
\text { - PSS specifications }\end{array}$ & $\begin{array}{l}\text { - User: requirement input, } \\
\text { specification evaluation } \\
\text { - Others: specification } \\
\text { evaluation }\end{array}$ & $\begin{array}{c}\text { G31, G32, G33 } \\
\text { Consistency of product, service and other PSS } \\
\text { elements: business model, organizational structure } \\
\text { as a system }\end{array}$ \\
\hline Design and integration & $\begin{array}{l}\text { - Concept design } \\
\text { - Detail design } \\
\text { - PSS integration }\end{array}$ & $\begin{array}{l}\text { - All stakeholders: concept } \\
\text { evaluation }\end{array}$ & $\begin{array}{c}\text { G41, G42, G43 } \\
\text { Compatibility of product, service and other PSS } \\
\text { elements: business model, organizational structure }\end{array}$ \\
\hline Test and refinement & $\begin{array}{l}\text { - Test implementation } \\
\text { - Feedback \& refinement }\end{array}$ & - User: test \& feedback & PSS is ready to deliver \\
\hline Implementation & $\begin{array}{l}\text { - PSS delivery } \\
\text { - Use } \\
\text { - Support }\end{array}$ & $\begin{array}{l}\text { - User: utilizations and } \\
\text { feedback }\end{array}$ & \\
\hline Retirement \& recycling & $\begin{array}{l}\text { - PSS retirement } \\
\text { - Disposal recycling }\end{array}$ & $\begin{array}{l}\text { - User: disposal } \\
\text { - Suppliers: disposal plan }\end{array}$ & End of life \\
\hline
\end{tabular}

Source: Tran and Park (2014). 


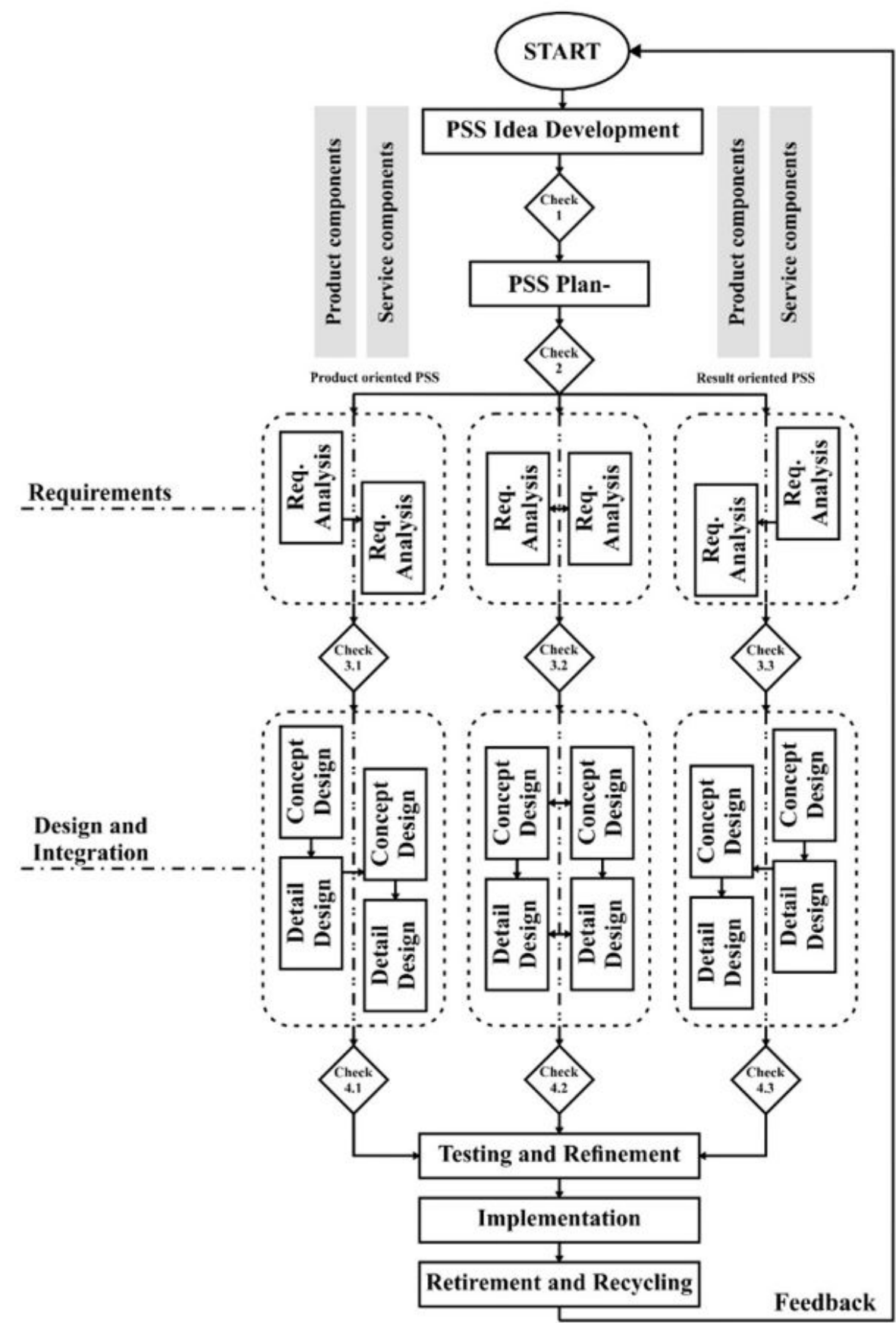

Figure 5. The proposed PSS development process by Tran and Park (2014).

function. The objective is validating the PSS architecture, the resulting arrangement of that architecture and the evaluation criteria that characterize this arrangement.

DETAILING - The activities to be carried out by the PSS and the solutions adopted are detailed. The breakdown of activities into sub-activities is relevant to detail the solution and specify each component of the PSS.

To achieve the objectives of the method, some tools are used which focus on the functionality of the product delivered to the customer. These tools allow greater flexibility to developers, covering a wide range of types of PSS, enabling the definition of conceptions and the design criteria. The first tool proposed is "the graph of interactors" used for the external functional analysis and helps to detail the external functions and constraints, as shown in Figure 6, E1, E2 and E3 represent the reactions, resistances or adaptations of the external environment to the PSS. A specific external analysis must be carried out 


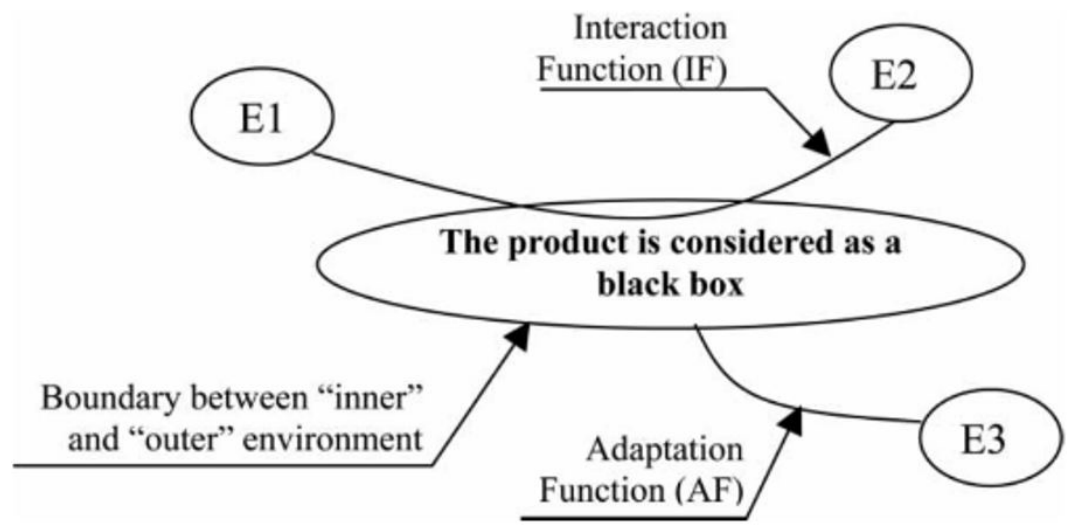

Figure 6. External functional analysis.

Source: Maussang, Zwolinski and Brissaud (2009).

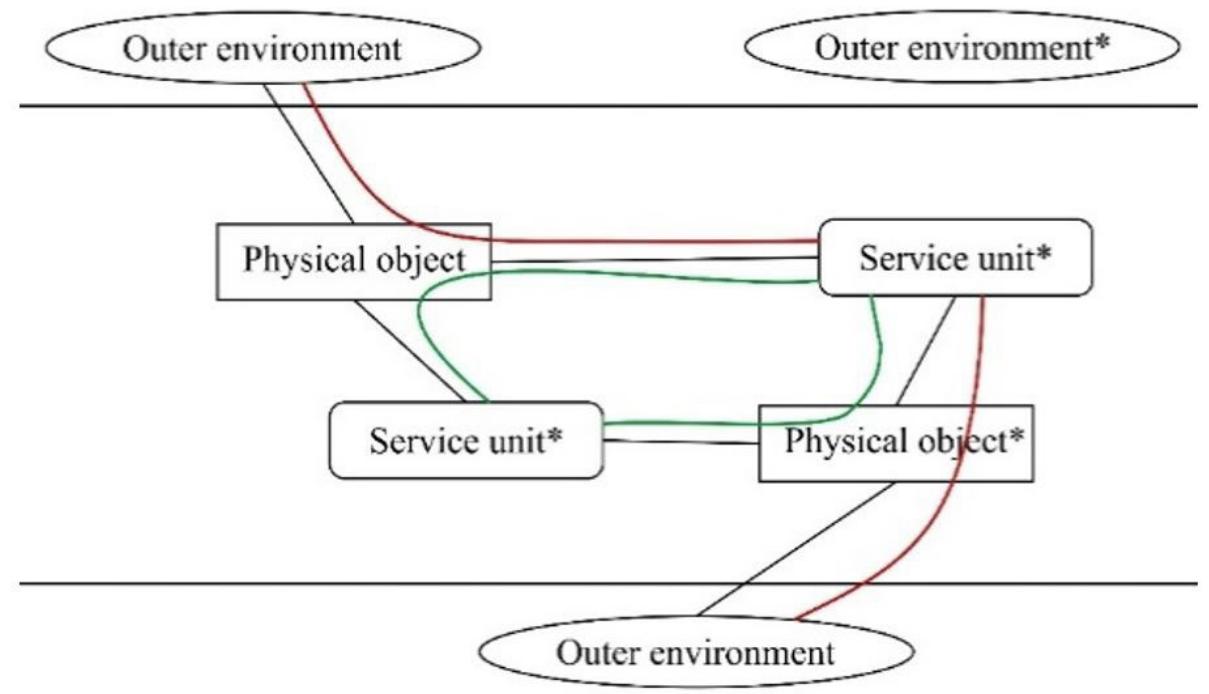

Figure 7. Functional block diagram representation. Source: Maussang, Zwolinski and Brissaud (2009).

for each stage of the product's life cycle (use, manufacture, maintenance, recycling). The product is, at this point in the development, considered as a black box, which can satisfy the customer's needs. The objective is to represent and express the expected needs and restrictions that can influence the product design.

Another tool proposed is "the functional block diagram" used for the representation of the PSS and to model and analyses the PSS structure. This tool helps to represent the influences of the external environment on the PSS, as shown in Figure 7, and its borders with the PSS (horizontal lines); the different components of the PSS (rectangles for products and rectangles with rounded edges for services) and their interactions with the external environment; the relationships among PSS components (black lines); the functional flows among the elements present in the external environment and which relate to the components of the PSS (lines in red); the technical functions of the PSS that represent the action flows among the components of the PSS (green lines).

The last tool proposed is "functioning scenarios" which is useful to present and situate solutions, to illustrate alternatives of solutions and to identify the potential of solutions, as shown in Figure 8. For this, the Structured Analysis and Design Technique (SADT) representation is used, which is based on the description of the activities. These scenarios should lead PSS developers to propose a sequence of activities to transform the elements of the system from an initial state to an end state. In this representation, principles of solutions and restrictions can be identified. 


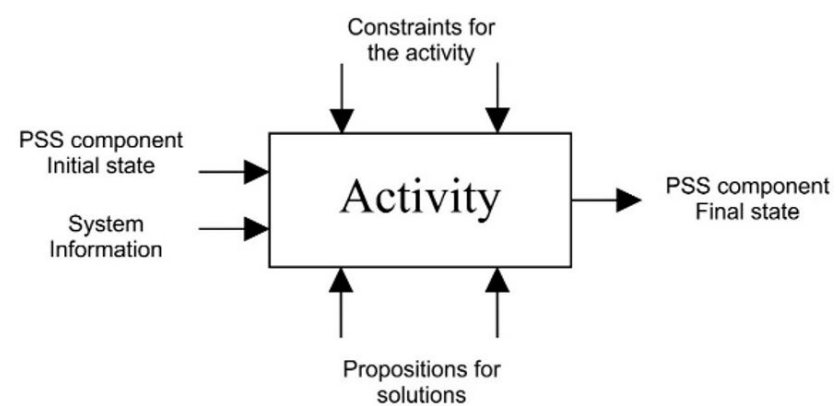

Figure 8. The SADT tool. Source: Maussang, Zwolinski and Brissaud (2009).

Despite the recognized need to determine the technical specifications for the development of physical objects, it turns out to be a constraint to achieve more strategic objectives, such as the effectiveness of the developed PSS. This is because the method places too high value on product development instead of its integrated development with the services to be offered.

\subsection{MEPSS - Methodology for Product-Service Systems}

The method focuses on creating new PSS and was designed to provide tools to enable this development, focusing on customer satisfaction and minimizing environmental and social impacts. It was proposed by Van Halen, Vezzoli and Wimmer (2005). It is guided towards system development and has a minor concern about product and service development individually. This method was developed by researchers and consultants working on PSS in association with partners, who provide support for their improvement.

It consists of a set of tools that support the activities of developing, implementing and monitoring product-service systems. MEPSS can be considered a generic model and can be used for the development of all types of PSS.

MEPSS seeks to understand the company's culture to generate the propositions for the PSS, which has as premise to correlating the actors and processes involved with the product and the service. Its structure supports the company's strategic analysis to choose the best alternatives for the new business model. The steps are divided into several processes enabled by the tools and are:

- Strategic analysis - Establishes the guidelines of the development process with an overview of the options for defining strategies aimed at specificities such as: stakeholders, regulation, restrictions, available technology, corporate culture, etc.;

- Exploring opportunities - Generates an overview of possible PSS proposals related to the analysis carried out previously;
- PSS idea development - Deploy the selected PSS ideas in greater depth and make the final selections for multiple PSS ideas;

- PSS concept design - Develops the detailed functionality of the selected PSS, defining the elements of the PSS and verifying its feasibility and sustainability.

- Development and preparation for implementation of PSS - Generates instructions for organizing, managing and controlling the PSS implantation as well as its documentation.

The method is organized in a modular approach which allows the developer to identify the most relevant steps for their context, with the option of not performing all the steps provided. Each step is structured in stages and is defined by a series of processes. The method covers gates among the steps as decision-making points, as shown in Figure 9. There is a website where details about the method, its steps, processes and support tools are provided.

In this method, products and services are treated as a single PSS offer, with no distinction between the service or product design, the focus is on the development of PSS as a system. Another relevant feature is the possibility of stakeholder cooperation in the development of the PSS with suggestions for the best performance of the PSS activities.

\subsection{Design framework for sustainable PSS customization}

This method was proposed by Song and Sakao (2017) and focuses on PSS customization in early design phase, proposing a design framework that covers the entire PSS development process. It is module-based and thus flexible according to the user needs. According the authors existing frameworks for PSS design are fragmented and insufficient to support customization, because most of them lack systematic and comprehensive support to specifically guide PSS customization from early requirements identification to design conflict resolving, and to later PSS configuration. This lack of systematic methodical support for the customization process may cause implementation difficulty in practice of PSS customization.

The proposed framework would systematically provide designers with standardized design process reference from the beginning requirements identification to the later concept configuration. Specifically, early conflict resolving mechanism in the framework aims to reduce possible defects in subsequent process of detailed design and delivery. Modularization process and methods of the framework will facilitate frequent design reuse and easier trace-back failures, and thus enhance design efficiency. The module-based configuration in the framework 


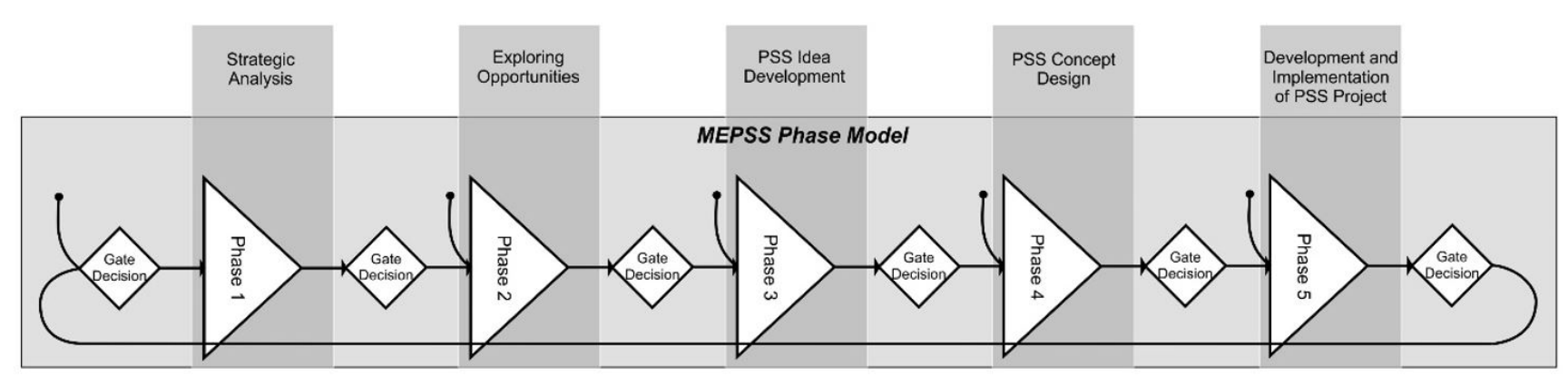

Figure 9. Phases and gates of MEPSS. Source: Van Halen, Vezzoli and Wimmer (2005)

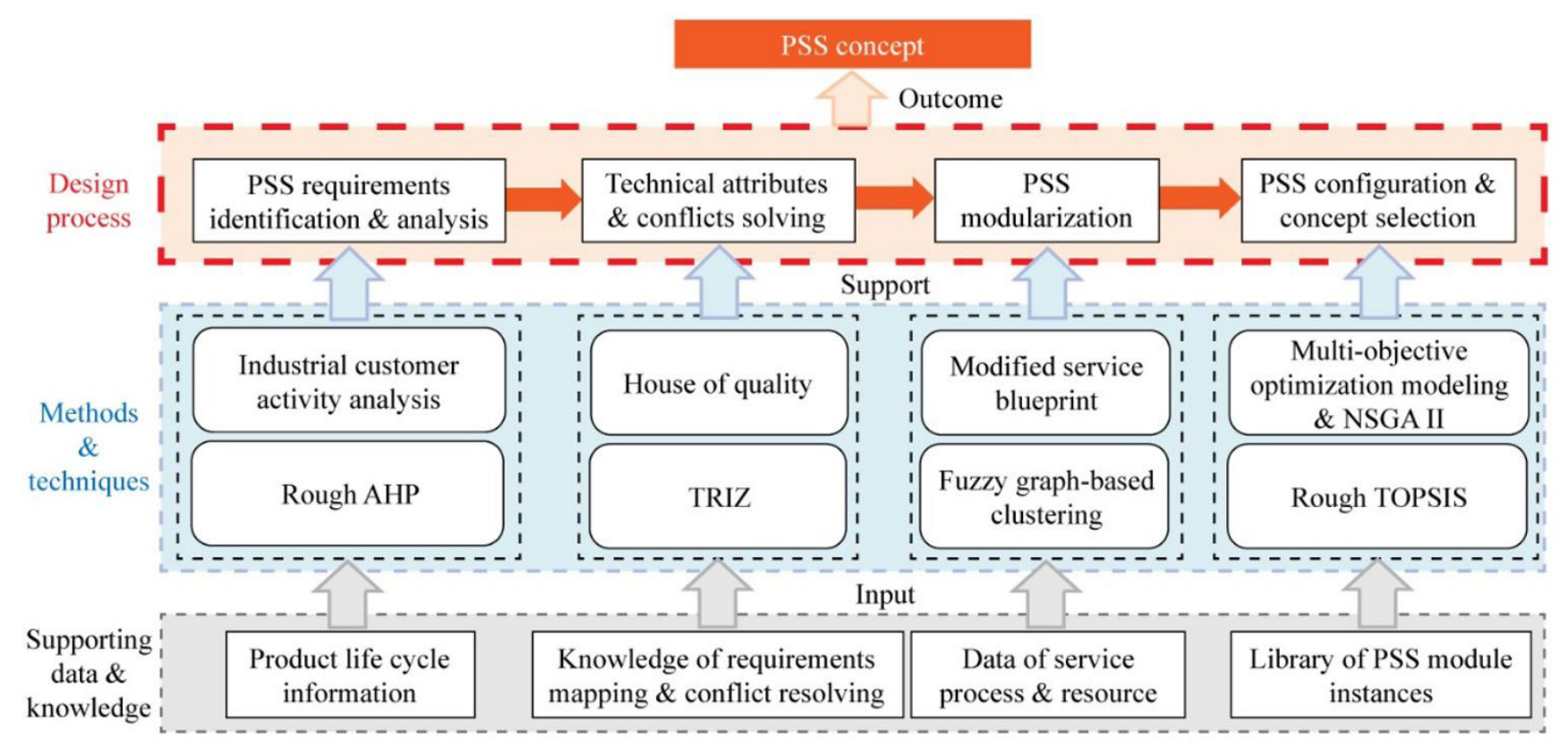

Figure 10. A design framework for sustainable Product/Service System. Source: Song and Sakao (2017).

could help the service provider to achieve flexible PSS customization (SONG; SAKAO, 2017).

Most of past researches have been dispersed in general description level without considering much about the framework implementation process or comprehensive design process. In particular, very few studies on design process for PSS customization have been conducted. For instance, PSS requirements generation from the analysis of customer activity cycles is often overlooked.

The overall PSS customization framework is structured in three levels of activities: the top-level of PSS design process, the middle level of design methods and techniques and the bottom level of supporting data and knowledge, as showed in Figure 10.

The top level of framework consists of four phases: PSS requirements identification and analysis; technical attributes and conflict resolving; PSS modularization; and
PSS configuration and concept selection. The middle level includes specific design methods and techniques to support the PSS design process. The bottom level of information and knowledge support is necessary as inputs. Product lifecycle information includes product monitoring information and customer feedbacks. With the key elements, the framework establishes throughput mechanism so that the output from one phase provides input to one or more of the following phases of PSS customization (SONG; SAKAO, 2017).

The method starts from requirements identification and ends with customized concept selection to obtain the most suitable PSS solution. Firstly, the PSS requirements are elicited and analyzed to get systematic and structured requirements. Then, the identified structured PSS requirements are converted into design attributes that designers can use. Meanwhile, potential design conflicts are also identified and resolved to facilitate later modularization 
and configuration. After that, the PSS provider scans the service solutions and capabilities to identify PSS components, and clusters them into modules. Finally, to effectively obtain reasonable customization concept, optimization model for module-based configuration is built and solved, respectively (SONG; SAKAO, 2017).

\section{Comparative analysis of methods}

One can categorize the steps of the methods described in: strategic analysis, design and implementation. In general, all the observed methods propose strategic analysis and the analysis of the opportunities involved. The exception is the PRODUCT-SERVICE SYSTEM DESIGN METHODOLOGY which starts by identifying customer requirements, but this would be expected since its approach is not geared to the development of the system, but to the operational elements of the PSS. On the other hand, the GENERIC DESIGN METHODOLOGY FOR DIFFERENT TYPES OF PSS and MEPSS propose a more complete approach suggesting a greater effort in the development of PSS and extending this analysis in two stages.

The design stage is common to all the methods analysed. The GENERIC DESIGN METHODOLOGY FOR DIFFERENT TYPES OF PSS and MEPSS methods are more concerned than others in their execution, presenting more details to developers who follow their guidelines. The SERVICE-ORIENTED PSS DEVELOPMENT PROCESS method performs the design of products and services separately. The DESIGN FRAMEWORK FOR SUSTAINABLE PSS CUSTOMIZATION method presents the PSS customization activity more effectively than the other methods.

The implantation phase is present only in the GENERIC DESIGN METHODOLOGY FOR DIFFERENT TYPES OF PSS and MEPSS methods due to the complexity achieved by the PSS, necessary for monitoring the implantation and for adjusting.
The GENERIC DESIGN METHODOLOGY FOR DIFFERENT TYPES OF PSS method presented two steps not observed in the other methods: "Test and Refinement" and "Retirement and Recycling". Table 3 summarizes the characteristics of the steps observed in the surveyed methods.

The SERVICE-ORIENTED PSS DEVELOPMENT PROCESS method does not present enough details to analyse the steps to be followed, nor indicate sources of information to meet this demand, such as websites, books or manuals. The GENERIC DESIGN METHODOLOGY FOR DIFFERENT TYPES OF PSS method does not have tools to support PSS development. The DESIGN FRAMEWORK FOR SUSTAINABLE PSS CUSTOMIZATION method presents enough details and tools for the development of PSS, however the PRODUCT-SERVICE SYSTEM DESIGN METHODOLOGY and MEPSS methods are much more complete in this premise. MEPSS, in particular, is the method that best meets this requirement having a website with detailed information for its use.

One of the restrictions that limit PSS applications in industry is the lack of practical guidelines for PSS developers. Most of the PSS development methods among the 46 observed in this survey do not have a step-by-step design process and the usefulness of these methods for PSS developers is restricted.

Regarding the strengths of each method, it was observed that the main positive characteristic of SERVICE-ORIENTED PSS DEVELOPMENT PROCESS is to allow a good integration among product functions and service functions, but it is restricted to cases of service-oriented PSS. The GENERIC DESIGN METHODOLOGY FOR DIFFERENT TYPES OF PSS provides stakeholder participation in the PSS development process but does not have an in-depth market analysis where the PSS will operate. PRODUCT-SERVICE SYSTEM DESIGN METHODOLOGY has good support for product development but does not analyse the context in which the PSS will be used and prioritizes the development of

Table 3. Characteristics of the steps observed in the surveyed methods.

\begin{tabular}{|l|l|l|l|l|l|}
\hline & $\begin{array}{l}\text { Service-oriented PSS } \\
\text { development process }\end{array}$ & $\begin{array}{l}\text { Generic design } \\
\text { methodology for } \\
\text { different types of } \\
\text { PSS }\end{array}$ & $\begin{array}{c}\text { Product-service } \\
\text { system design } \\
\text { methodology }\end{array}$ & $\begin{array}{l}\text { Mesign framework } \\
\text { for sustainable PSS } \\
\text { customization }\end{array}$ \\
\hline Strategic analysis & Existing step & $\begin{array}{l}\text { Existing step, has a } \\
\text { detailed approach to } \\
\text { execution }\end{array}$ & Existing step & $\begin{array}{l}\text { Existing step, has a } \\
\text { detailed approach to } \\
\text { execution }\end{array}$ & $\begin{array}{l}\text { Existing step, has a } \\
\text { detailed approach to } \\
\text { execution }\end{array}$ \\
\hline Conception & $\begin{array}{l}\text { Existing step. Runs } \\
\text { separately for } \\
\text { products and services }\end{array}$ & $\begin{array}{l}\text { Existing step, has a } \\
\text { detailed approach to } \\
\text { execution }\end{array}$ & Existing step & $\begin{array}{l}\text { Existing step, has a } \\
\text { detailed approach to } \\
\text { execution }\end{array}$ & Existing step \\
\hline Implantation & Non-existent step & Existing step & Existing step & Existing step & Non-existent step \\
\hline
\end{tabular}


the product rather than the PSS itself. MEPSS prioritizes the company's strategic analysis to choose the best path for the new business model, focusing on the development of PSS. The method DESIGN FRAMEWORK FOR SUSTAINABLE PSS CUSTOMIZATION is very efficient in PSS customization, because it meets client needs of a systematic and comprehensive support for customization of PSS.

The methods do not make a distinction in relation to the type of PSS to be developed; they consider they can be used regardless of the type of PSS chosen. There is no evidence in this research that this can cause less efficiency and/or effectiveness in the developed PSSs. The exception noted is the SERVICE-ORIENTED PSS DEVELOPMENT PROCESS method, which was developed exclusively for service-oriented PSS cases.

The GENERIC DESIGN METHODOLOGY FOR DIFFERENT TYPES OF PSS is like the SERVICE-ORIENTED PSS DEVELOPMENT PROCESS, both provide evaluations at the end of the phases for approval and release for the beginning of the next phase. The first is different from the second because suggests that product component is developed before the service component in the case of a product-oriented PSS, and the reverse in the case of service-oriented or results-oriented PSS.

In the SERVICE-ORIENTED PSS DEVELOPMENT PROCESS method, the authors guide the development of the product and service to be simultaneous and with constant exchange of information and feedbacks.
The roles and responsibilities of stakeholders in co-creating the value offering are not clearly defined in the SERVICE-ORIENTED PSS DEVELOPMENT PROCESS and PRODUCT-SERVICE SYSTEM DESIGN METHODOLOGY methods. In these methods, co-creation and its implementation are presented in insufficient details for its execution.

The integration of products and services is presented as one of the main objectives in all methods. The processes involved in this integration are well detailed in all the analysed methods, but the tasks to be performed in each step are not mentioned in the SERVICE-ORIENTED PSS DEVELOPMENT PROCESS method.

The methods SERVICE-ORIENTED PSS DEVELOPMENT PROCESS and PRODUCT-SERVICE SYSTEM DESIGN METHODOLOGY are more focused on the development of products and/or services and the other three on the PSS development. This leads to different points of view on the approach to be followed, the level of detail to be considered, the decision-making process, and the necessary level of detailed information. Therefore, the company interested in developing a PSS to its business reality must consider these particularities which are summarized in the Table 4.

\section{Conclusions}

There are Many proposed methods and tools for PSS development as summarized in Table 1. However, it is observed that there is no agreement in the literature

Table 4. Comparative among the analyzed methods.

\begin{tabular}{|c|c|c|c|c|c|}
\hline & $\begin{array}{l}\text { Service-oriented PSS } \\
\text { development process }\end{array}$ & $\begin{array}{c}\text { Generic design } \\
\text { methodology for } \\
\text { different types of PSS }\end{array}$ & $\begin{array}{l}\text { Product-service } \\
\text { system design } \\
\text { methodology }\end{array}$ & MEPSS & $\begin{array}{c}\text { Design framework } \\
\text { for sustainable PSS } \\
\text { customization }\end{array}$ \\
\hline Type of PSS & Service-oriented & All types & All types & All types & All types \\
\hline Main feature & $\begin{array}{l}\text { Suitable for service } \\
\text { providers which wish } \\
\text { to migrate to a PSS }\end{array}$ & $\begin{array}{l}\text { Strong participation } \\
\text { of stakeholders in the } \\
\text { development process. }\end{array}$ & $\begin{array}{l}\text { Emphasis on product } \\
\text { development which } \\
\text { will support PSS. }\end{array}$ & $\begin{array}{l}\text { Product and service } \\
\text { are considered as a } \\
\text { single PSS offer and } \\
\text { there is no distinction } \\
\text { between service } \\
\text { design and product } \\
\text { design. } \\
\end{array}$ & $\begin{array}{l}\text { It meets client needs } \\
\text { for PSS customization }\end{array}$ \\
\hline Goal & $\begin{array}{l}\text { To increase service } \\
\text { competitiveness }\end{array}$ & $\begin{array}{l}\text { Present a generic } \\
\text { proposal for the } \\
\text { development of } \\
\text { different types of PSS. }\end{array}$ & $\begin{array}{l}\text { Development of } \\
\text { PSS focusing on the } \\
\text { specifications of the } \\
\text { products involved in } \\
\text { the system. }\end{array}$ & $\begin{array}{l}\text { Focus on minimizing } \\
\text { the environmental } \\
\text { and social impact } \\
\text { generated by the } \\
\text { PSS. } \\
\end{array}$ & $\begin{array}{l}\text { Focus on minimizing } \\
\text { the environmental } \\
\text { and social impact } \\
\text { generated by the PSS }\end{array}$ \\
\hline Scope & PSS development & $\begin{array}{l}\text { Broader scope, from } \\
\text { the development } \\
\text { of PSS to product } \\
\text { recycling. }\end{array}$ & PSS development & $\begin{array}{l}\text { In addition to the } \\
\text { development it has } \\
\text { an additional step } \\
\text { which deals with the } \\
\text { implantation of the } \\
\text { PSS. }\end{array}$ & $\begin{array}{l}\text { Among the methods } \\
\text { analyzed, it has } \\
\text { the most restricted } \\
\text { scope, ranging from } \\
\text { requirements to the } \\
\text { configuration of the } \\
\text { PSS }\end{array}$ \\
\hline
\end{tabular}


Table 4. Continued...

\begin{tabular}{|c|c|c|c|c|c|}
\hline & $\begin{array}{l}\text { Service-oriented PSS } \\
\text { development process }\end{array}$ & $\begin{array}{c}\text { Generic design } \\
\text { methodology for } \\
\text { different types of PSS }\end{array}$ & $\begin{array}{l}\text { Product-service } \\
\text { system design } \\
\text { methodology } \\
\end{array}$ & MEPSS & $\begin{array}{c}\text { Design framework } \\
\text { for sustainable PSS } \\
\text { customization } \\
\end{array}$ \\
\hline Type of PSS & Service-oriented & All types & All types & All types & All types \\
\hline Steps and gates & $\begin{array}{l}\text { "Strategic Planning", } \\
\text { "Idea Generation and } \\
\text { Selection", "Service } \\
\text { Design" and "Product } \\
\text { Development", }\end{array}$ & $\begin{array}{l}\text { "Requirement } \\
\text { Analysis", "Design } \\
\text { and Integration", "Test } \\
\text { and Refinement", } \\
\text { "Implementation" } \\
\text { and "Retirement \& } \\
\text { Recycling" }\end{array}$ & $\begin{array}{l}\text { "Customer's } \\
\text { "Requirements", } \\
\text { "Functions } \\
\text { Deployment", } \\
\text { "Scenarios" and } \\
\text { "Detailing" }\end{array}$ & $\begin{array}{l}\text { "Strategic analysis", } \\
\text { "Exploring } \\
\text { opportunities", "PSS } \\
\text { idea development", } \\
\text { "PSS concept } \\
\text { design" and } \\
\text { "Development and } \\
\text { preparation for } \\
\text { implementation of } \\
\text { PSS" }\end{array}$ & $\begin{array}{l}\text { "PSS requirements } \\
\text { identification and } \\
\text { analysis", "Technical } \\
\text { attributes' conflicts } \\
\text { resolving", "PSS } \\
\text { modularization", } \\
\text { "PSS configuration } \\
\text { and concept } \\
\text { selection"" }\end{array}$ \\
\hline $\begin{array}{l}\text { Indication of tools } \\
\text { to support PSS } \\
\text { development } \\
\end{array}$ & No & No & Yes & Yes & Partly \\
\hline $\begin{array}{l}\text { Checkpoint } \\
\text { among phases }\end{array}$ & Yes & Yes & No & Yes & No \\
\hline $\begin{array}{l}\text { Stakeholder } \\
\text { participation in } \\
\text { PSS development }\end{array}$ & No & Yes & No & Yes & Yes \\
\hline Strong points & $\begin{array}{l}\text { Allows a good } \\
\text { integration between } \\
\text { the product functions } \\
\text { and the service } \\
\text { functions. }\end{array}$ & $\begin{array}{l}\text { Participation of } \\
\text { stakeholders in the PSS } \\
\text { development process. }\end{array}$ & $\begin{array}{l}\text { Allows a better } \\
\text { support to the } \\
\text { product development. }\end{array}$ & $\begin{array}{l}\text { Favors strategic } \\
\text { analysis of the } \\
\text { company background } \\
\text { to choose the } \\
\text { best way for the } \\
\text { company's new } \\
\text { business model }\end{array}$ & $\begin{array}{l}\text { Focus on } \\
\text { requirements in } \\
\text { product lifecycle use }\end{array}$ \\
\hline Weak points & $\begin{array}{l}\text { Restricted to cases of } \\
\text { service-oriented PSS. }\end{array}$ & $\begin{array}{l}\text { Lack of in-depth } \\
\text { strategic market } \\
\text { analysis where PSS } \\
\text { will operate. }\end{array}$ & $\begin{array}{l}\text { The methodology } \\
\text { does not analyze } \\
\text { the business context } \\
\text { where PSS will be } \\
\text { used. The method } \\
\text { focuses on product } \\
\text { development. }\end{array}$ & $\begin{array}{l}\text { Shows little concern } \\
\text { for the development } \\
\text { of product and } \\
\text { service in isolation. }\end{array}$ & $\begin{array}{l}\text { Uses different tools } \\
\text { that have been } \\
\text { designed for other } \\
\text { applications and does } \\
\text { not fit them for the } \\
\text { development of a } \\
\text { PSS. }\end{array}$ \\
\hline
\end{tabular}

regarding the prevalence of a method or a set of criteria that guides the method selection process. Analyzing the papers in this literature review, there were no approaches widely accepted by both scientific and professional communities, which lead to a guidance on the adoption of one method over others. The state-of-the-art position of this area of knowledge still does not allow the development of a widely accepted method that may be used in different types of PSS, industry sectors and degrees of the Servitization process. On the other hand, it is believed that there is no feasibility for developing a method with this range of application and it is also evident that few methods are published in sufficient detail to allow their operational use.

No paper was found that establishes an analysis on the performance of the several methods under discussion that could serve as a parameter for the selection of a method with prominent characteristics. It is understood that performing such analysis is a complex task, because it requires a great effort, including applications, with unreliable results, due to the many variables involved in the applications and results obtained.

However, in the analysis of the methods discussed, it is observed that their approaches, steps and characteristics are similar, with no observable predominance of one method over another. These methods have particularities that distinguish them from each other, such as the greater focus on the integrated development of products and services. During this analysis it was noted that researchers in the PSS field tend to show a subjective bias while choosing a PSS development method. Despite the impartiality of PSS research so far, it would be preferable that the methods were evaluated by third party groups and not only by their developers.

The observed cases of application in the papers are quite specific and there is little information on the details of the PSS implementation process, which leads to a lower 
reliability for the replication of the presented reports. There are still no studies showing the development of a PSS without the support of a method would result in longer execution times and unsatisfactory results in the medium and short terms. On the other hand, due to the complexity of a PSS development process, it can be inferred that the use of a method would efficiently guide the implementation of a PSS.

In the analysis it was observed that the criteria used for choosing a method for PSS development are not well defined yet. It is suggested that PSS developers make their choice based on the following criteria:

- Characteristics of the method to verify its potentialities and restrictions according to the objectives to be achieved in the development of the PSS;

- The information and infrastructure necessary to use the method;

- Other elements related to the viability of its execution, such as the method's adaptation to the characteristics of the company's business model.

Out of the 46 methods identified in preliminary research, only 5 met the established requirements. The strict selection process shows that there are still few papers regarding the details of applying a method. The lack of detailed information and effectively tested models creates uncertainty for manufacturing companies seeking the best approach to implement a PSS. There is one noted exception: MEPSS. This method provides detailed steps online of the implementation process, whereas other methods are restricted to limited spaces provided by scientific journals which demands a research justification, a method of research, among other requirements thus restricting the available information. Therefore, it is suggested that in future works researchers should focus on papers with more case studies and more detailed information regarding the methods used and perceived results.

\section{References}

AKASAKA, F. et al. Development of a knowledge-based design support system for Product-Service Systems. Computers in Industry, v. 63, n. 4, p. 309-318, 2012a.

AKASAKA, F. et al. Development of PSS design support system: knowledge-based design support and qualitative evaluation. Procedia CIRP, v. 3, n. 0, p. 239-244, 2012 b.

ALVAREZ, R. L. P. Uma proposta de modelo de maturidade aplicada à servitização de empresas de bens de consumo duráveis. 2012. Tese de Doutorado. (Programa de Pós Graduação em Engenharia Naval) - Universidade de São Paulo, São Paulo, 2012.
BAINES, T. et al. Servitization: Revisiting the state-of-the-art and research priorities. International Journal of Operations \& Production Management, n. July, p. 1-28, 2016.

BAINES, T. S. et al. State-of-the-art in product-service systems. Proceedings of the Institution of Mechanical Engineers. Part B, Journal of Engineering Manufacture, v. 221, n. 10, p. 1543-1552, 2007.

BAINES, T.; LIGHTFOOT, W. H. Servitization of the manufacturing firm. International Journal of Operations \& Production Management, v. 34, n. 1, p. 2-35, 2013.

BEUREN, F. H. et al. Análise de conteúdo de publicações em Sistemas Produto-Serviço. Produção Online, v. 14, n. 1, p. 31-57, 2014.

BIOLCHINI, J. C. A. et al. Scientific research ontology to support systematic review in software engineering. Advanced Engineering Informatics, v. 21, n. 2, p. 133-151, 2007.

CLAYTON, R. J.; BACKHOUSE, C. J.; DANI, S. Evaluating existing approaches to product-service system design. Journal of Manufacturing Technology Management, v. 23, n. 3, p. 272-298, 2012.

DYBA, T.; DINGSOYR, T. Empirical studies of agile software development: a systematic review. Information and Software Technology, v. 50, n. 9-10, p. 833-859, 2008.

GOEDKOOP, M. J. et al. Product Service systems, Ecological and Economic Basics. Amersfoort: Report for Dutch Ministries of Environment (VROM) and Economic Affairs (EZ), 1999.

KIM, S. et al. Development of an innovation model based on a service-oriented Product Service System(PSS). Sustainability, v. 7, n. 11, p. 14427-14449, 2015.

KIM, Y. S. et al. A systematic design framework for productservice systems and its implementation. In INTERNATIONAL CONFERENCE ON SERVICE SCIENCE AND INNOVATION, 5., 2013, Porto. Anais... IEEE, 2013.

KRUEGER, M. W. et al. Integrative service innovation: An industrial use case. In: CONFERENCE ON BUSINESS INFORMATICS, 17., Anais... IEEE, 2015. p. 217-223.

LEVY, Y; ELLIS, T. J. A systems approach to conduct an effective literature review in support of information systems research. Informing Science, v. 9, p. 181-211, 2006.

LUCILE, T.; ALAN, L.; DANIEL, B. New PSS design method of a pneumatic energy system. Procedia CIRP, v. 30, p. 48$53,2015$.

MAHUT, F. et al. Survey on product-service system applications in the automotive industry. IFAC Proceedings Volumes (IFAC-PapersOnline), v. 48, n. 3, p. 840-847, 2015.

MARILUNGO, E. et al. Open innovation for ideating and designing new Product Service Systems. Procedia CIRP, v. 47, p. 305-310, 2016.

MARILUNGO, E.; PERUZZINI, M.; GERMANI, M. An Integrated Method to Support PSS Design within the Virtual Enterprise. Procedia CIRP, v. 30, p. 54-59, 2015. 
MARQUES, P. et al. A Methodology for Product-service Systems Development. Procedia CIRP, v. 7, p. 371-376, 2013.

MATTHYSSENS, P.; VANDENBEMPT, K.; BERGHMAN, L. Value innovation in business markets-breaking the industry recipe. Industrial Marketing Management, v. 35, p. 751-761, 2006.

MAUSSANG, N. et al. A model for designing product-service systems using functional analysis and agent based model. In: INTERNATIONAL CONFERENCE ON ENGINEERING DESIGN, 16., 2007, Paris. Anais... ICED, 2007.

MAUSSANG, N.; ZWOLINSKI, P.; BRISSAUD, D. Product-service system design methodology: from the PSS architecture design to the products specifications. Journal of Engineering Design, v. 20, n. 4, p. 349-366, 2009.

MENDES, G. H. S. et al. Product-Service System (PSS) design process methodologies: a systematic literature review. In: INTERNATIONAL CONFERENCE ON ENGINEERING DESIGN, 20., 2015. Milan. Proceedings... Design Society, 2015. p. 291-300.

MONT, O. Introducing an integrated engine service system. Manufacturing Engineer, v. 80, n. 3, p. 133-138, 2001.

MUTO, K.; KIMITA, K.; SHIMOMURA, Y. A Guideline for Product-Service-Systems Design Process. Procedia CIRP, v. 30, p. 60-65, 2015.

NGUYEN, H. N. et al. Operationalizing IPS2 development process: A method for realizing IPS2 developments based on Process-based project planning. Procedia CIRP. v. 16, p. 217-222, 2014.

PERUZZINI, M.; MARILUNGO, E. Design for Sustainability in PSS: Evidences of QFD-Based method application. In: ISPE INC. INTERNATIONAL CONFERENCE ON TRANSDISCIPLINARY ENGINEERING, 23., 2016, Curitiba. Proceedings... 2016.

PERUZZINI, M.; MARILUNGO, E.; GERMANI, M. Functional and ecosystem requirements to design sustainable P-S. Advances in Transdisciplinary Engineering, v. 1, p. 768-777, 2014a.

PERUZZINI, M.; MARILUNGO, E.; GERMANI, M. A QFD-based methodology to support Product-Service design in manufacturing industry. In: INTERNATIONAL CONFERENCE ON ENGINEERING, TECHNOLOGY AND INNOVATION, 20., Bergamo. Proceedings... IEEE, 2014b.

PERUZZINI, M.; MARILUNGO, E.; GERMANI, M. Technical - Business Design Methodology for PSS. Netherlands: IOS, 2015. p. 513-522. Advances in Transdisciplinary Engineering.

PEZZOTTA, G. et al. Definition of a PSS Engineering Environment: from the Theoretical Methodology to the Platform Implementation. In: XXI SUMMER SCHOOL
"FRANCESCO TURCO” - INDUSTRIAL SYSTEMS ENGINEERING. Proceedings... 2016a

PEZZOTTA, G. et al. Towards a methodology to engineer industrial product-service system - Evidence from power and automation industry. CIRP Journal of Manufacturing Science and Technology, v. 15, p. 19-32, $2016 \mathrm{~b}$.

RONDINI, A. et al. Service engineering framework: The adoption of simulation to design and configure ProductService solutions. In: INTERNATIONAL CONFERENCE ON ENGINEERING, TECHNOLOGYAND INNOVATION, 2014, Bergamo. Proceedings... IEEE, 2014.

SAKAO, T.; PAULSSON, S.; MIZUYAMA, H. Inside a PSS design process: Insights through protocol analysis. In: INTERNATIONAL CONFERENCE ON ENGINEERING DESIGN, 18., 2011, Copenhague. Proceedings... ICED, 2011.

SAKAO, T.; SANDSTRÖM, G. Ö.; MATZEN, D. Framing research for service orientation of manufacturers through PSS approaches. Journal of Manufacturing Technology Management, v. 20, n. 5, p. 754-778, 2009.

SONG, W.; SAKAO, T. A customization-oriented framework for design of sustainable product/service system. Journal of Cleaner Production, v. 140, p. 1672-1685, 2017.

SUTANTO, A. et al. Product-service system design concept development based on product and service integration. Journal of Desert Research, v. 13, n. 1, p. 1-19, 2015.

TRAN, T. A.; PARK, J. Y. Development of integrated design methodology for various types of product - Service Systems. Journal of Computational Design and Engineering, v. 1, n. 1, p. 37-47, 2014.

VAN HALEN, C.; VEZZOLI, C.; WIMMER, R. Methodology for Product-Service System Innovation, How to implement clean, clever and competitive strategies in European industries. Assen, Netherlands: Royal Van Gorcum, 2005.

VASANTHA, G. V.A. et al. A review of product-service systems design methodologies. Journal of Engineering Design, v. 23, n. 9 , p. 635-659, 2012.

VISINTIN, F. A methodology to support the development of integrated product-service solutions. In: INTERNATIONAL CONFERENCE ON ADVANCES IN PRODUCTION MANAGEMENT SYSTEMS. 2010Anais... APMS, 2010.

YANG, L. J.; XING, K.; LEE, S. H. A new design approach for PSS Conceptual Development. Advanced Materials Research, v. 605-607, p. 104-109, 2013.

YANG, X. et al. A practical methodology for realizing product service systems for consumer products. Computers \& Industrial Engineering, v. 56, n. 1, p. 224-235, 2009.

ZINE, P. U. et al. A conceptual framework for product service system design for machine tools. Benchmarking, v. 23, n. 5, p. 1227-1248, 2016. 